\title{
SINGULARIDADES DA EDUCAÇÃO POPULAR DO PARANOÁ- ITAPOÃ (DF): UMA CONSTRUÇÃO ENTRE UNIVERSIDADE DE BRASÍLIA E MOVIMENTO POPULAR ORGANIZADO
}

\author{
Maria Clarisse Vieira ${ }^{1}$ \\ Julieta Borges Lemes Sobral ${ }^{2}$ \\ Renato Hilário dos Reis ${ }^{3}$
}

\section{RESUMO}

Este artigo trata das singularidades da Educação Popular constituídas desde 1985 entre a Universidade de Brasília e o movimento popular das cidades do Paranoá e Itapoã no Distrito Federal, Brasil. Para compreender essas especificidades, são realizadas análises bibliográficas de pesquisas acadêmicas que tratam do efeito desse processo educativo na vida de educandos, educadores populares, professores da rede pública e estudantes universitários. O resultado dessa análise indica como características desse projeto de Educação Popular: a constituição de sujeitos a partir do entrelaçamento do ser de amor-poder-saber; o aprendizado pelos educandos de que os problemas de seu cotidiano são oportunidades de superação e não de desistência; o aprendizado pelos educadores da importância da construção coletiva; e, por fim, o processo formativo dos estudantes da UnB que destaca a indissociabilidade da relação teoria-prática.

Palavras-chave: Educação Popular. Educação de Jovens e Adultos. Formação de Educadores.

\footnotetext{
1Doutora em Educação. Professora associada da Faculdade de Educação e do Programa de Pós-graduação em Educação da Universidade de Brasília. Coordenadora do Grupo de Ensino, Pesquisa e Extensão em Educação Popular e Estudos. ORCID: https://orcid.org/0000-0001-5924-0488. E-mail: mariaclarissev@gmail.com

${ }^{2}$ Doutora em Educação. Servidora do Ministério da Educação. Membropesquisadora do Grupo de Ensino-Pesquisa-Extensão em Educação Popular e Estudos Filosóficos e Histórico-Culturais - GENPEX/FE/UnB. ORCID: https://orcid.org/0000-0002-4544-9771. E-mail: jujucampanha@gmail.com.

${ }^{3}$ Doutor em Educação). Professor da Universidade de Brasília. Membro pesquisador do Grupo de Ensino, Pesquisa e Extensão em Educação Popular e Estudos Filosóficos e Histórico-Culturais-GENPEX. ORCID: https://orcid.org/0000-0002-5046-2057. E-mail: hilarioreis@uol.com.br.
} 


\section{SINGULARITIES OF POPULAR EDUCATION OF THE CITIES OF PARANOÁ AND ITAPOÁ (DF): CONSTRUCTION BETWEEN UNIVERSITY OF BRASILIA AND ORGANIZED POPULAR MOVEMENT}

\section{ABSTRACT}

This article deals with the singularities of Popular Education established since 1985 between the University of Brasilia and the popular movement of the cities of Paranoá and Itapoã in the Federal District, Brazil. In order to understand these specificities, bibliographic analyzes of academic research are carried out that address the effect of this educational process on the lives of students, popular educators, public school teachers and university students. The result of this analysis indicates as characteristics of this Popular Education project: the constitution of subjects from the intertwining of the being of love-power-knowledge; the learning by students that the problems of their daily lives are opportunities to overcome and not give up; the learning by educators of the importance of collective construction; and, finally, the training process of UnB students, which highlights the inseparability of the theory-practice relationship.

Keywords: Popular Education. Youth and Adult Education. Teacher Training.

\section{SINGULARIDADES DE LA EDUCACIÓN POPULAR EN LAS CIUDADES DE PARANOÁ E ITAPOÁ (DF): CONSTRUCCIÓN ENTRE LA UNIVERSIDAD DE BRASILIA Y EL MOVIMIENTO POPULAR ORGANIZADO}

\section{RESUMEN}

Este artículo trata sobre las singularidades de la Educación Popular establecida desde 1985 entre la Universidad de Brasilia y el movimiento popular en las ciudades de Paranoá e Itapoã en el Distrito Federal, Brasil. Para comprender estas especificidades se realizan análisis bibliográficos de investigación académica que abordan el efecto de este proceso 
educativo en la vida de estudiantes, educadores populares, docentes de escuelas públicas y estudiantes universitarios. El resultado de este análisis señala como características de este proyecto de Educación Popular: la constitución de sujetos a partir del entrelazamiento del ser amor-poderconocimiento; los estudiantes aprenden que sus problemas diarios son oportunidades para superar y no darse por vencidos; el aprendizaje por parte de los educadores de la importancia de la construcción colectiva; $y$, finalmente, el proceso de formación de los estudiantes de la UnB, que destaca la inseparabilidad de la relación teoría-práctica.

Palabras clave: Educación Popular. Educación de Jóvenes y Adultos. Formación Docente.

\section{INTRODUÇÃO}

Este artigo é um dos resultados de investigação que analisou e contribuiu para o processo de dialogia-dialética entre a Educação Popular do Paranoá e Itapoã e a Educação de Jovens, Adultos e Idosos Trabalhadores de uma Escola Classe da Rede Pública de Ensino do Paranoá-Distrito Federal.

Para atingir o objetivo central da pesquisa, buscamos investigar e desvelar as vozes e sentidos da Educação Popular, constituída historicamente entre a Faculdade de Educação da Universidade de Brasília e o Movimento Popular do Paranoá-Itapoã ${ }^{4}$

Importante esclarecer que o Movimento Popular do ParanoáItapoã é aqui representado pelo Centro de Cultura e Desenvolvimento do Paranoá - Cedep, fundado em 2 de agosto de 1987: "o Cedep representa jurídica-politicamente a continuidade dos projetos que estão sendo desenvolvidos, as incansáveis lutas, os movimentos de resistência e a conquista do Paranoá" (JESUS, 2007, p. 36). Assim, neste trabalho, as terminologias Movimento Popular do Paranoá-Itapoã, Cedep ou apenas Movimento Popular se equivalem.

\footnotetext{
${ }^{4}$ Esclareço ao leitor que de 1985 a 2005 tínhamos a parceria apenas com o Movimento Popular do Paranoá. Em 2005, a população organizada do Itapoã faz articulação com o Movimento Popular do Paranoá, aqui representado pelo Centro de Cultura e Desenvolvimento do Paranoá - Cedep, e, desde então, denominamos o Movimento Popular do Paranoá-Itapoã ou, apenas, Cedep.
} 
O Paranoá e o Itapoã são duas Regiões Administrativas do Distrito Federal que estão muito próximas e que se assemelham pela história de resistência dos moradores pela fixação e garantia do direito a saúde, educação, saneamento básico, entre outros. No Paranoá, esse processo de ocupação e enfrentamentos ocorre na década de 1980 e, no Itapoã, mais recentemente, na primeira década dos anos 2000. Em 2005, as histórias do Paranoá e do Itapoã se encontram, se costuram, e é desse chão que emergem as análises deste artigo.

Em 1985, o Movimento Popular do Paranoá-Itapoã procura a Faculdade de Educação - FE da Universidade de Brasília-UnB, na pessoa da professora Marialice Pitaguary, para as primeiras tratativas de uma parceria. Importante salientar que, nesse período, a FE/UnB não funciona no período noturno. O currículo do curso de Pedagogia está voltado predominantemente para a formação de professores para o público infantil. Essas duas circunstâncias fazem-nos imaginar, por alguns segundos, a sensação de insegurança que a professora Marialice Pitaguary deve ter sentido ao se ver frente ao desafio de construir, conjuntamente com o Movimento Popular, uma Educação de Jovens e Adultos que não somente ensinasse a leitura, a escrita e o cálculo, mas estivesse a serviço da melhoria das condições de vida da população do Paranoá e, hoje, também do Itapoã.

Maria de Lourdes Pereira Santos, uma das lideranças históricas do Movimento Popular do Paranoá-Itapoã, conta-nos que, no primeiro encontro que ocorre com a professora Marialice, os jovens percebem que ela não acredita muito na proposta do grupo do Paranoá. Ao identificarem isso, os jovens mudam a tática e convidam a professora para uma reunião no Paranoá. Ao chegar, uma multidão de pessoas a espera. O que ela deve ter sentido diante daquela multidão? Será que ela tinha todas as respostas? Com certeza, não. Mas, com sua coragem, disse sim. Desafia-se a dar o primeiro passo, mesmo não sabendo onde vai chegar. Começa com o retalho de suas mãos. Coordena essa ação conjunta de 1985 a 1989, quando retorna à sua terra natal, Ouro Fino, Minas Gerais.

Nesse momento, o professor Renato Hilário dos Reis, recém distribuído como Técnico em Assuntos Educacionais da Universidade de Brasília, aceita o desafio de dar continuidade à caminhada recém- 
iniciada pela professora Marialice Pitaguary. Não começa do zero, começa a partir dos passos dados pela professora, pelo coletivo de estudantes da UnB e pelos jovens do Movimento Popular. Renato não vem sozinho, como registra Gilene ao relatar sua chegada ao Projeto:

Nessa época em que comecei é que a professora Marialice da UnB saiu e aí veio o professor Renato [...] O grupo da UnB aumentou. Vieram os professores Renato Hilário dos Reis, Cristiano Alberto Muniz, Antônio Vilar Marques de Sá [da educação] e Eugênio, Stela Maris, e posteriormente Maria Isabel Magalhães [da linguística]. (REIS, 2011, p. 176).

Em conversas informais com estudantes da FE/UnB que participam desse momento inicial de construção, contam-me que o "pau"5 entre Faculdade de Educação/UnB e Movimento Popular é grande. Não têm muitas certezas de como fazer essa proposta. Discussões, conflitos, concordâncias e discordâncias fazem parte desse processo. Professor Renato coordena o projeto de 1987 até 2016, quando se aposenta da Universidade. Dando continuidade ao trabalho, com muita generosidade e coragem, assume a professora $\mathrm{Dr}^{\mathrm{a}}$ Maria Clarisse Vieira. Agora, com novos enfrentamentos.

Mão a mão, retalho a retalho, voz a voz, dia a dia, sol a sol, chuva a chuva, a relação FE/UnB e Movimento Popular do ParanoáItapoã vai se constituindo. Dessa caminhada histórica emerge o Grupo de Ensino, Pesquisa, Extensão em Educação Popular e Estudos Filosóficos e Histórico-Culturais - Genpex/FE/UnB. Grupo, formalizado em 2000 no Conselho Nacional de Desenvolvimento Científico e Tecnológico - CNPq, que abarca e abraça toda a produção realizada decorrente dessa parceria ${ }^{6}$, de 1985 até os dias de hoje.

Cada ser humano que chega ao Genpex/FE/UnB deixa sua marca, sua produção. O que existe hoje teve um primeiro passo. Uma caminhada que é histórica, que modifica as circunstâncias antigas e

\footnotetext{
${ }^{5} \mathrm{~A}$ palavra pau está sendo utilizada no sentido de brigas, conflitos.

${ }^{6}$ No que se refere à relação entre Universidade de Brasília e Movimento Popular, as denominações utilizadas no texto são: parceria, Projeto Paranoá-Itapoã, ação conjunta.
} 
entrega, para nós, circunstâncias outras que nos permitem continuar a caminhada e superar os desafios que são postos:

A história não é senão a sucessão das diferentes gerações, cada uma das quais explora os materiais, os capitais, as forças produtivas que lhe são transmitidas pelas gerações precedentes; assim sendo, cada geração, por um lado, continua o modo de atividade que lhe é transmitido, mas em circunstâncias radicalmente transformadas, e, por outro lado, ela modifica as antigas circunstâncias entregando-se a uma atividade radicalmente diferente; chega-se a desnaturar esses fatos pela especulação, fazendo-se da história recente a finalidade da história anterior. (MARX; ENGELS, 1998, p. 46-47, grifo nosso)

Desse trabalho histórico de mais de 30 anos, indagamo-nos (SOBRAL, 2018) sobre a singularidade da Educação Popular que vem sendo constituída no Paranoá-Itapoã. Para compreender essa especificidade, buscamos quatro pesquisas que perpassam esse processo histórico de constituição, de 1985 a 2015: um livro-tese de doutorado e três dissertações de mestrado. O principal parâmetro para escolha desses trabalhos é a intencionalidade dos quatro trabalhos em investigar o efeito-repercussão dessa ação conjunta, FE/UnB e Movimento Popular do Paranoá-Itapoã, na vida dos sujeitos envolvidos, educandos, educadores e estudantes-pesquisadores da UnB.

O primeiro é o livro-tese do professor Dr. Renato Hilário dos Reis "A constituição do ser humano: amor-poder-saber na educação/alfabetização de jovens e adultos". Trabalho que registra a síntese da construção Movimento Popular e Universidade de Brasília, ocorrida nas décadas de 1980 e 1990, base de toda a produção do Genpex/FE/UnB. Além desse livro-tese, selecionamos três dissertações que investigam a repercussão dessa parceria na vida de educandos(as), educadores(as) e estudantes-pesquisadores da UnB egressos(as).

A primeira dissertação é a de Airan Almeida de Lima, que investiga os educandos e as educandas egressas da experiência do 
Projeto Paranoá que estão na Rede Pública de Ensino. O título da pesquisa é "Participação e Superação do Fracasso Escolar: o caso do Projeto de Alfabetização de Jovens e Adultos da cidade do ParanoáDF", trabalho defendido e aprovado em 1999, na FE/UnB.

A segunda dissertação é de Leila Maria de Jesus, que aprofunda o olhar dos educadores e educadoras egressas do Projeto Paranoá que estão na Rede Pública. Essa produção está consubstanciada na dissertação "A repercussão da atuação de educadores populares do Cedep/UnB na Escola Pública do Paranoá", defendida e aprovada em 2007, na FE/UnB.

Finalizando essa tríade, está a dissertação de Sttela Pimenta Viana, que investiga estudantes da UnB, pedagogas e pedagogos, egressas(os) do Projeto Paranoá e que trabalham com a Educação de Jovens, Adultos e Idosos Trabalhadores. O título desse trabalho é "As significações e repercussões do percurso formativo de pedagogos(as) egressos(as) do Projeto Paranoá em suas trajetórias profissionais na Educação de Jovens e Adultos". Trabalho defendido e aprovado no ano de 2012, na FE/UnB.

A análise desses trabalhos responde ao objetivo central deste artigo: compreender a singularidade da Educação Popular constituída historicamente, desde 1985, entre a Universidade de Brasília e o Movimento Popular do Paranoá-Itapoã.

\section{ANÁLISE DOS TRABALHOS}

A tese de Reis (2000) desafia-se a responder a pergunta apresentada pelo Movimento Popular do Paranoá-Itapoã à FE/UnB: como ensinar a ler, escrever e calcular, contribuindo para a superação das exigências de existência e sobrevivência do ser humano, continuando a caminhada histórica de nossos ancestrais de avanço da constituição humana?

Dessa indagação, vem se construindo uma proposta políticopedagógica para a Alfabetização de Jovens e Adultos do Movimento Popular do Paranoá-Itapoã: apropriação de leitura, escrita e cálculo, mas, intrinsecamente, constituição de uma participação de jovens, adultos e idosos na solução dos problemas vividos pelos moradores 
do Paranoá, hoje, também Itapoã7. Não é uma receita; é uma proposta coletiva que vai se constituindo no percurso e que precisa estar aberta e em diálogo com cada momento histórico vivido por essa ação conjunta.

Essa construção histórica é sistematizada, inicialmente, na tese de Reis (2000), e, dez anos depois, em um livro, Reis (2011). Reis (2011) esclarece que na tese, em 2000, o título de seu trabalho é "A constituição do sujeito político, epistemológico e amoroso na Alfabetização de Jovens e Adultos do Paranoá". Em 2011, quando da escrita do seu livro, uma mudança significativa ocorre, tendo em vista as ressignificações da caminhada que está em permanente movimento. O título do livro passa a ser "A constituição do ser humano: amor, poder e saber na educação/alfabetização de jovens e adultos". Há uma inversão do político com o amoroso.

$\mathrm{Se}$, na tese, o político precede o amoroso, com seu desenvolvimento práxico acumulado, Reis (2011) descobre que o Amor precede o Poder e o Saber, e que a constituição de um Sujeito Amoroso é base e condição da constituição simultânea de um Sujeito Político e de um Sujeito Epistemológico.

Essa amorosidade, acolhimento mútuo, perpassa todos os momentos da proposta historicamente construída no ParanoáItapoã. É uma marca histórica. O trabalho inicia-se em sala de aula, espaço micro de convivência e aprendizagem coletiva, em que educandos, educadores e estudantes-pesquisadores da UnB encontram-se pela primeira vez. Encontro banhado pela acolhida e aprendizagem mútua:

A descoberta do acolhimento, do ser acolhido, de ter direito a si mesmo sem ser rejeitado, sem ter medo de sê-lo. A possibilidade de falar e expressar seu sentir, seja dor, seja alegria, diante daquilo que o aflige em si mesmo. Mas tendo alguém para partilhar e compartilhar. Ouvir. Acolher. Dar atenção. (REIS, 2011, p. 72).

\footnotetext{
${ }^{7}$ Lembro ao leitor que a ampliação da parceria com o Itapoã ocorre em 2005, quando a população organizada do Itapoã-Distrito Federal demanda da Universidade de Brasília e do Centro de Cultura e Desenvolvimento do Paranoá - Cedep ajuda para iniciar a Alfabetização de jovens e adultos.
} 
Nesse espaço de acolhida, discutem e escolhem, coletivamente, a situação-problema-desafio que representa a turma de alfabetização. Essas situações

$$
\begin{aligned}
& \text { referem-se às necessidades econômicas, } \\
& \text { financeiras, sociais, culturais e afetivas que } \\
& \text { caracterizam o cotidiano vivido/enfrentado pelos } \\
& \text { moradores do Paranoá, como decorrência da lógica } \\
& \text { excludente [...] produzida do modo de produção } \\
& \text { dominante no país. (REIS, 2011, p. 161). }
\end{aligned}
$$

Em seguida, todas as turmas são convidadas a participar do espaço macro de convivência e aprendizagem coletiva, denominado Fórum. É uma grande aula coletiva em que se estabelecem as linhas orientadoras de todo o processo alfabetizador. Nesse espaço, apresentam-se as situações-problemas-desafios das turmas e decidese qual delas é a prioritária para o grupo. As demais não são excluídas; apenas são colocadas em uma sequência de prioridades.

A situação-problema-desafio escolhida transforma-se no centro do processo alfabetizador, outra singularidade da Educação Popular do Paranoá-Itapoã. Pergunta-se: como as diversas linguagens dialogam com a situação-problema-desafio? Em cada turma, essa indagação traz à tona diversas atividades ligadas à Língua Portuguesa, Matemática, Ciências, História, Geografia, Artes, Informática. Elabora-se um texto coletivo. O texto coletivo é também uma peculiaridade dessa construção histórica. A partir do levantamento das várias significações da situação-problema-desafio, costura-se um texto coletivo com as vozes de todos da turma: texto, frase, palavra, sílaba, letra. Tudo pode ser explorado pelo(a) educador(a) no processo de alfabetização.

Não mais as cartilhas prontas como centralidade, mas o texto criado coletivamente. Educadores e educandos têm a oportunidade de se apropriar do conhecimento historicamente acumulado, mas não ficam somente nele, pois também são produtores e autores de novos conhecimentos. Produção de um conhecimento encarnado na vida dos sujeitos. Sobre a produção do texto coletivo, é importante registrar que, em 2020, é publicado livro do Genpex que investiga especificamente "As significações do texto coletivo no processo 
alfabetizador de jovens e adultos do Paranoá e Itapoã/UnB/Cedep"8. Nesse livro, destacamos uma parte da conclusão do trabalho que diz que os textos coletivos

são diálogos (escuta e fala elaborantes) de vida e existência entre e com as/os alfabetizandas/os, alfabetizadoras/es, professoras/es e estudantes da UnB. Constitui-se como momento singular de participação da/o alfabetizanda/o e, como tal, do exercício de dessilenciamento (perda do seu medo de ser). (VIEIRA; REIS; RIOS, 2020, p. 125)

O processo de alfabetização torna-se um espaço estratégico para a construção de um conhecimento que é parte da exercitação da superação das situações-problemas-desafios da população. Quais estratégias podem contribuir para a superação dessa situaçãoproblema-desafio? Questão que também é pensada-planejada em cada turma e no fórum da Alfabetização de Jovens e Adultos. $O$ encaminhamento, por ser coletivo, fortalece o processo de exercitação de sua superação. "Não estou sozinho no mundo, tenho a quem recorrer". Definidos os encaminhamentos de superação da situação-problema-desafio, estabelecem-se as estratégias a serem seguidas. Nem sempre essa exercitação gera a plena superação da situação-problema-desafio. Porém, essa exercitação coletiva é um aprendizado fundamental na perspectiva histórico-cultural marxista de desenvolvimento humano: é necessário lutar para sobreviver, existir, tornar-se humano.

Nessa concepção, o trabalho é condição primeira, por ser o alicerce do desenvolvimento humano, como defende Engels (1979, p. 215): "O trabalho, porém, é muitíssimo mais do que isso. É a condição básica e fundamental de toda a vida humana. E em tal grau que, até certo ponto, podemos afirmar que o trabalho criou o próprio homem" e como premissa de Marx (1996, p. 211): "[...] o trabalho é um processo de que participam homem e a natureza [...] atuando

\footnotetext{
${ }^{8}$ Este livro foi elaborado coletivamente nas reuniões mensais do GENPEX/FE/UnBMantendo a caminhada, Tem a participação de educadoras/es populares/Cedep e de graduandas/os-graduados/graduadas/mestres/doutores que foram se constituindo ao longo da história da ação de aprendizado e desenvolvimento humano conjunto movimento popular organizado do Paranoá-Itapoã-Cedep e GENPEX/FE/UnB.
} 
assim sobre a natureza externa e modificando-a, ao mesmo tempo modifica sua própria natureza". Trabalho como relação de transformação recíproca homem-natureza, que Pino me ajuda a compreender como basilar para a concepção de desenvolvimento humano em Vigotski:

A idéia de Marx, de que "não é a consciência que determina a vida, mas a vida que determina a consciência" [...] aplica-se, segundo Vigotski, a todas as funções psicológicas (pensamento, linguagem, percepção, memória etc.). O que significa que, se por vida entendemos as novas condições de existência criadas pelo homem e não as existentes na natureza, estas funções não são o produto desta mas daquelas. (PINO, 2000, p. 62, grifo nosso)

A vida, nossos pensamentos, linguagem, percepção, memória, não como algo dado natural ou apenas biológico, mas como construções sociais e históricas que se constituem ao produzirmos nossa existência humana, na relação recíproca ser humano-natureza. Produção da existência que, no capitalismo, tem como marca estrutural um embate de classe entre capital e trabalho. Sobre isso, Vigotski (2000, p. 25), em seu Manuscrito de 1929, afirma:

Atrás do poder psicológico da palavra sobre as funções psicológicas está o poder real do chefe e do subordinado. A relação das funções psicológicas é geneticamente correlacionada com as relações reais entre as pessoas: regulação pela palavra, conduta verbalizada $=$ poder - subordinação.

Compreendo com Reis, Engels, Marx, Pino e Vigotski, que nos constituímos nas relações sociais, não mecanicamente, mas dialeticamente. Nós também individual-coletivamente constituímos essas relações sociais. Relações sociais contraditórias e de antagonismo de classe, em que estão em disputa capital e trabalho, que são a natureza do nosso desenvolvimento humano. Relações de contradição que constituem a história da humanidade, a minha história, a história do Genpex/FE/UnB, a história do Paranoá-Itapoã e 
o desdobramento político-pedagógico da situação-problemadesafio (escolha, exercitação da superação e possível superação).

O desdobramento político-pedagógico da situaçãoproblema-desafio, com seus avanços e não avanços, nos convida a realizar uma permanente avaliação do processo. O que pode melhorar? Socializa-se, a partir das múltiplas vozes e sentidos, o vivido, conscientes de que sempre temos o que avançar. A socialização é realizada como finalização dos momentos de partilha e convivência. É um espaço de comemoração, onde saber e sabor fazem-se presentes. Assim, geralmente, com um lanche coletivo, celebra-se esse encontro, uma verdadeira festa de finalização e reabertura do novo ciclo, de novos enfrentamentos.

Em sua tese, Reis $(2000,2011)$ investiga a caminhada histórica de luta do Paranoá-Itapoã e como os sujeitos se constituem nesse processo. Realiza cinco entrevistas, sendo quatro com alfabetizadoras e lideranças do Movimento Popular e uma com um alfabetizando. Maria de Lourdes Pereira dos Santos (Lourdes); Maria Creuza Evangelista de Aquino (Creuza); Gilene Maria dos Reis (Gilene); Eva Lopes Sampaio (Eva); Jerry Adriani da Rocha Nascimento (Jerry). Dessa conversa, que é denominada pelo autor de "Roda de Prosa", corrobora-se a tese de que no Projeto de Alfabetização e Formação em Processo de Alfabetizadores do Paranoá-Itapoã, aqui denominado de Projeto Paranoá-Itapoã, há um sujeito de amor, poder e saber em constituição. Sujeito de amor, como aquele que acolhe e é acolhido. Sujeito de poder, que conquista e exerce poder. Sujeito de saber, que produz conhecimento.

Nessa tese, Eva, ao falar dessa construção políticopedagógica, registra a marca da luta, do trabalho coletivo e da superação: "A pessoa não desistia. Levantava novamente [o barraco] com ajuda dos outros" (REIS, 2011, p. 151). A história dos moradores do Paranoá é uma história de resistência coletiva. Vêm do Nordeste, com muita dificuldade, superando a fome, a morte de filhos, a dor. Vêm no pau de arara, com muito sofrimento. Querem trabalhar e conseguem. Trabalham duro e constroem Brasília. Suor, pó, mãos e pés calejados. Deixam muito de si nesta terra. Alguns perdem suas vidas. A construção inicial acaba. Querem ficar, continuar vivendo nessa terra prometida. Porém, não encontram morada. Precisam 
batalhar para garantir direitos mínimos. Luta coletiva, resistência e superação dos problemas são marcas dos sujeitos que se constituem no Projeto Paranoá-Itapoã.

Eva ressalta a marca da acolhida: "O contato entre alfabetizador e alfabetizando era grande e carinhoso. Isso levou muitos a continuar e terminar os estudos" (REIS, 2011, p. 153). Ainda sobre a acolhida, aparece a importância da escuta ao educando "É assim que eles conseguem se libertar daquela coisa de ficar em silêncio. A Educação Popular no Paranoá-Itapoã garante esse desenvolvimento com os alunos" (p. 159). A dimensão da escuta como parte estratégica de romper o silêncio estruturante que os educandos e as educandas chegam à escola. Acolhida que olha $e$ chama pelo nome "É claro que vai ocorrer uma apresentação inicial da turma. Eu ia olhar para você, conversar, perguntar seu nome e é claro você ia ficar de cabeça baixa"(p. 167). O olhar, o chamar pelo nome, gestos singelos que muito representam para aquele e aquela que são sempre invisibilizados na sociedade.

Creuza e Gilene reforçam a dimensão do coletivo, de se fortalecer no coletivo, de vencer a timidez, as dificuldades de relacionamento com o outro:

Eu tinha, então, dificuldade de relacionamento. De descobrir as outras pessoas, de divulgar o que eu sabia para as outras e eu não sabia criar as oportunidades. [...] esse meu desenvolvimento dentro da sociedade e da política aprendi no e com o projeto. (REIS, 2011, p. 181).

A convivência como um desafio a ser superado em uma sociedade que valoriza o indivíduo, o particular, o meu, o seu. Vencer barreiras de estar com, de participar, de se colocar sem medo. Gilene e Creusa reforçam esse grande aprendizado dessa iniciativa conjunta e popular.

Sobre a participação e exercitação política na sociedade, Gilene relata duas aulas que vivenciam esse processo coletivamente com os estudantes. A primeira, com o educando Valmir: "Depois dessas discussões, Valmir reuniu e coordenou seus colegas de emprego e entraram na justiça contra a empresa, que tinha assinado 
[...] um contrato de seis meses e queria anulá-lo" (REIS, 2011, p. 188). A escola e a sala de aula como espaços privilegiados de se discutir e encaminhar soluções para a garantia dos direitos dos trabalhadores.

Sobre a segunda aula, Gilene relata a participação de educandos e educandas no processo de discussão do orçamento participativo do Paranoá nos anos de 1996, 1997 e 1998: "Esse coletivo de alunos saiu fazendo campanha nas quadras explicando às pessoas da importância de se votar na reforma e ampliação da escola. Foi uma grande mobilização e um movimento histórico" (p. 192).

Outro elemento importante reforçado por Gilene, é o reconhecimento que o processo educacional é uma troca de saberes em que cada um contribui com o que é, o que sabe, o que pode, como ressalta Creuza: "Olha! Eu estou aqui não como professora, eu não vou estar aqui na frente e vocês atrás de mim. Estamos aqui juntos e não há ninguém superior. Estamos aqui para trabalhar, aprender e crescer juntos." (Ibidem, p. 199). Uma constituição de sujeitos de saber que não é uma prerrogativa apenas da Universidade. Cada um tem o direito de dizer e pensar a partir de seu lugar, não havendo hierarquização de saberes, mas sim, saberes diferentes.

Jerry também ressalta em sua fala a importância do tratamento acolhedor que é realizado nas salas do Projeto ParanoáItapoã: "Aqui no Cedep, quando eu não sabia, a professora ia lá com aquele sorriso e dizia: Ah! Deixa eu ver...ficou bonito [...] Então, você ficava contente de pegar o caderno e dar o caderno novamente para ela corrigir" (REIS, 2011, p. 210). Reforça ainda que, dentro da Rede Pública, enfrenta muitos desafios, encontra apoio em alguns professores "Existem professores que são ótimos. A professora Mara é ótima, tem muita paciência" e, em outros, não "[...] tem muito professor da Fundação Educacional [atualmente Secretaria de Estado de Educação do DF] que trata muito mal seus alunos. O tratamento devia ser outro. Todo mundo é ser humano" (Ibidem, p. 215-216).

Seguimos nossa análise com o trabalho de Lima (1999). Em seu mestrado, acompanha os educandos e as educandas do Projeto que vão para a Rede Pública. A pesquisa ocorre nos anos de 1997, 1998 e 1999. Lima (1999, p. 22) indaga-se se 
[...] a participação no supletivo está conseguindo realizar a transformação dos educandos e dos educadores enquanto sujeitos críticos e participativos $e_{1}$ simultaneamente, isso tem contribuído para a superação do fracasso escolar [...].

Para aprofundar tal questão, inicia sua investigação a partir da aplicação de 243 questionários com 25 questões que se subdividiam em três grandes campos: o primeiro visando conhecer as condições sócio-econômico-geográficas; o segundo, as condições educacionais e, o terceiro, os posicionamentos políticos a partir de suas escolhas eleitorais.

Da compilação desse material, Lima (1999) tem uma surpresa ao identificar uma tendência dos egressos da Educação Popular do Paranoá em resistir e continuar os estudos na Rede Pública de Ensino:

Ao se analisar a trajetória escolar dos $23,4 \%$ de alunos do supletivo ${ }^{9}$ que são egressos da educação popular e que estavam estudando no período de 1995 a 1998, 26,3\% deles haviam abandonado os estudos, $11,3 \%$ foram transferidos e $62,4 \%$ permaneceram estudando. (LIMA, 1999, p.260)

De cada 100 alunos egressos da Educação Popular, 62 permaneceram estudando na fase 3 ( $2^{\circ}$ Segmento, de acordo com a legislação atual na Secretaria de Estado de Educação do DF, mais conhecido como $8^{a}$ série do Ensino Fundamental) da Educação de Jovens e Adultos - EJA.

Os egressos da Educação Popular têm uma disposição maior em resistir à tendência do supletivo a reproduzir o fracasso escolar. Essa primeira diagnose de Lima (1999) faz com que ele precise aprofundar ainda mais a questão e, para isso, realiza entrevistas com 2 educandos da Rede Pública egressos da Educação Popular do Paranoá, com a diretora da escola pública, que era também

\footnotetext{
${ }^{9}$ Supletivo é a nomenclatura para a Educação de Jovens, Adultos e Idosos Trabalhadores utilizada pela Lei n 5.692/1971, Lei de Diretrizes e Bases da Educação, que é anterior à Lei n 9.394/1996, que está em vigor. Em 2018, a denominação legal é Educação de Jovens e Adultos.
} 
presidente do Centro de Cultura e Desenvolvimento do Paranoá CEDEP, e com a coordenadora da escola pública, que já tinha sido alfabetizadora e coordenadora da Educação Popular do CEDEP.

Lima (1999) descobre, com esse aprofundamento, o porquê dos educandos egressos da Educação Popular terem essa tendência de permanecer na escola e concluir seus estudos:

Os fatores que possibilitaram essa permanência no supletivo advêm da capacidade dos egressos, da diretora e da coordenadora do supletivo de estabelecer inter-relações com os estudos escolares às situações problemas da vida, criando uma resistência ao fracasso escolar do supletivo e a predisposição dos egressos à participação voluntária nas atividades em sala. Isso provocou uma atitude de resistência frente aos obstáculos ao prosseguimento dos estudos refletindo a metodologia da educação popular em sua ênfase na participação social tornando-se assim, no grande fator de resistência dos egressos aos obstáculos sociais e escolares à continuidade dos estudos. (LIMA, 1999, p. 260, grifo nosso)

Como destacado, "uma atitude de resistência frente aos obstáculos", essa descoberta de Lima (1999) desvela que há uma aprendizagem singular na proposta da Educação Popular do Paranoá, que tem contribuído para o prosseguimento dos estudos dos educandos e educandas egressas: aprendem que problema não é para desistir, mas para superar. Descoberta que contraria, inclusive, uma hipótese inicial da dissertação de Lima (1999) de que a Educação Popular do Paranoá nada interfere na vida do educando e da educanda que estão na Rede Pública, conforme destaca Reis (1993).

Uma das questões levantadas, à época, era que, ao se desenvolver uma experiência de alfabetização de jovens e adultos, tendo por inerente a preocupação da inserção desses na luta coletiva dos moradores, tinha-se que perguntar se isso estava ocorrendo ou não. Faz-se, então, um questionamento básico fundamental: onde estão e o que fazem hoje os egressos, os alfabetizados, do projeto de 
alfabetização de jovens e adultos da Vila Paranoá? Continuam a ler e escrever? A exercitar a leitura, a escrita, o cálculo? Estão inseridos na luta coletiva dos moradores? Uma coisa e outra? Nenhuma das duas coisas? (REIS, 1995, p.4 mimeo).

Lima (1999) inicialmente tem uma dúvida em relação à repercussão do processo educacional realizado pelo Movimento Popular em parceria com a FE/UnB. Considera que a Educação Popular não interfere na vida do egresso. Porém, com o levantamento quantitativo realizado na Rede Pública, descobre uma tendência do egresso da Educação Popular em continuar seus estudos. Perguntase o porquê disso. Descobre, com o aprofundamento realizado nas entrevistas, que a espécie humana avança e se torna humana, superando as exigências de existência e sobrevivência. Esse é o sentido vivido e ensinado pelos educandos egressos da Educação Popular do Paranoá, quando não desistem da escola.

Lima (1999) coloca uma lupa sobre a trajetória dos educandos e educandas egressas, destacando a singularidade da participação popular como uma participação mais abrangente e comprometida com a transformação social. A categoria fundamental de sua investigação é a participação. Exaustivamente, discute as nuances da participação no âmbito político, epistemológico, administrativo, pedagógico e na gestão escolar. Faz isso buscando caracterizar a singularidade da participação popular vivenciada no Projeto ParanoáItapoã como contribuidora à superação do fracasso escolar. Ressalta, por fim, que os(as) educandos(as) egressos(as) têm uma tendência à permanência e superação do fracasso escolar porque aprendem na Educação Popular do Paranoá que o sentido da vida e do viver está não em desanimar diante dos problemas, mas em enfrentá-los, superá-los e ir fazendo a vida.

Jesus (2007) também traz sua contribuição na caracterização das singularidades da Educação Popular do Paranoá ao se indagar: onde estão os educadores e as educadoras da Educação Popular do Paranoá? Será que eles estão na Rede Pública? Se estão, a experiência no Projeto Paranoá-Itapoã traz alguma contribuição para o cotidiano escolar que vivenciam na Rede Pública? Mais uma investigação que 
estuda o efeito repercussão dessa ação conjunta Genpex/FE/UnB e Cedep.

A pesquisa de Jesus (2007) é realizada nos anos de 2006 e 2007 e investiga os educadores e educadoras egressas da Educação Popular que estão na Rede Pública de Ensino. Esse objeto de pesquisa emerge a partir da trajetória de Jesus no Movimento Popular do Paranoá e, também, como professora/diretora de uma escola da Rede Pública de Ensino.

A experiência nesses dois espaços, quando na posição de direção, lhe fez perceber hipoteticamente que havia um diferencial entre os educadores da Rede Pública que são egressos do Movimento Popular. Mas que diferencial é esse? Formula, então, sua principal pergunta de pesquisa:

As educadoras populares que passaram pelo processo de aprendizado conjunto com outros/as educadores/as, alfabetizandos/as e alunos/as da UnB, aprenderam/incorporaram essa perspectiva e a levam/desenvolvem na Rede Pública de Ensino? Se desenvolvem, de que natureza e com que intensidade? (JESUS, 2007, p. 110).

Inicia sua investigação fazendo um levantamento dos educadores da Rede Pública que são residentes no Paranoá. Nesse levantamento, encontra 76 educadores da rede que são residentes no Paranoá. Dos 76 educadores, 25 passam pela orientação/participação na educação popular do Cedep, na Alfabetização de Jovens e Adultos. Desses 25 encontrados, Jesus (2007) seleciona cinco educadores para fazer seus aprofundamentos: Francilene Noronha, Maria das Graças, Maria de Fátima Oliveira, Sílvio Soares e Silvana Silveira.

As conclusões de Jesus (2007), indicam que os(as) alfabetizadores(as) populares que estão na Rede Pública sentem a diferença, principalmente no que diz respeito à natureza do coletivo:

Nossos educadores egressos têm um olhar que vai além dascondições materiais de ensino na escola pública. Têm um olhar para as condições subjetivas em que se dá a construção do fazer pedagógico dentro da escola pública. Não estão alheios às 
dificuldades materiais apontadas acima, mas parecem entender que estas podem ser superadas na medida em que se instala o espírito coletivo no conjunto da escola. (JESUS, 2007, p.160, grifo nosso)

Se no Movimento Popular há uma dinâmica semanal de favorecimento da construção coletiva, na Rede Pública parece que isso não ocorre, segundo pesquisa de Jesus (2007). Os educadores egressos da Educação Popular sentem esse problema, esse isolamento, essa solidão. Mas de que natureza de coletivo sentem falta? Um coletivo que tem como premissa a acolhida mútua, como destaca Reis:

O fato de ser ouvido, escutado, acolhido pelo outro, por si só estabelece uma dialogia. O ser falante quer ser ouvido, escutado, compreendido, respondido, e por sua vez, responder à resposta do outro. [...] o ouvinte é tão ativo quanto o locutor, porque sua escuta é elaborante/elaborativa, acolhe o outro, deixa-se penetrar por ele, aprender com ele, elabora, reelabora o que ouve e sente, e dá sua resposta. $E$, nessa alternância de sujeitos que falam e ouvem elaboradamente, estes se desenvolvem e se constituem. Se sentem acolhidos pelo outro e acolhem o outro. (REIS, 2000, p. 136, grifo nosso)

A descoberta de Jesus (2007), amparada nos fundamentos trazidos por Reis $(2000,2011)$, problematiza os simulacros de coletivo que vivenciamos, em que a participação do grupo se resume apenas a uma consulta aos participantes do processo, e a decisão final está resguardada a uma única pessoa. Não é esse coletivo que Jesus (2007) e Reis $(2000,2011)$ estão defendendo. A natureza de coletivo defendida tem a ver com a acolhida humana, a escuta elaborante, a atenção, o olho no olho, o respeito profundo ao que o outro diz, mesmo discordando dele, e, principalmente, uma deliberação final que emerge a partir da vez, voz e decisão de todos, uma resultante dialética em que eu não venço, o outro não vence, nós vencemos e aprendemos juntos, estamos abertos a ver e ampliar posições 
individuais, sem exclusões. Aqui não cabe a indiferença do olhar, do corpo, a desqualificação antecipada; a base é a acolhida humanaexistencial, em que a multiplicidade dos pontos de vista, das vozes e sentidos se sobrepõe à busca pelo absoluto:

[...] cada ideia é a ideia de alguém, situa-se em relação a uma voz que a carrega e a um horizonte a que visa. No lugar do absoluto, uma multiplicidade de pontos de vista: os das personagens e o do autor que lhes é assimilado;e eles não conhecem privilégios nem hierarquias. A revolução de Dostoiévski, no plano estético (e ético), é comparável à de Copérnico, ou ainda à de Einstein, no plano do conhecimento do mundo físico [...] já não há centro, e vivemos na relatividade generalizada. (BAKHTIN, 2010, p. XX-XXI, grifo nosso)

Natureza de coletivo, que é de acolhida das múltiplas vozes e sentidos. Aprendizado de destaque na Educação Popular do ParanoáItapoã, conforme resultado encontrado pela pesquisa de Jesus (2007). $\mathrm{Na}$ Rede Pública, ao se defrontarem com as dificuldades e negativas para o estabelecimento de uma relação múltipla e coletiva, os educadores entrevistados por Jesus (2007) desenvolvem iniciativas individuais-subjetivas para enfrentar o isolamento e a voz absoluta: buscam mudar a relação social dentro da sala de aula, com o fortalecimento da turma; e trabalham na perspectiva do diálogo com os pares, procurando, pela argumentação e vivência, contagiar outros educadores. Iniciativas individuais-subjetivas que almejam rupturar a lógica hegemônica do isolamento e constituir espaços de múltiplas vozes, múltiplos sentidos, de uma natureza de coletivo que é de acolhida humano-existencial.

Jesus (2007, p. 191) conclui que existe uma contribuição singular do Movimento Popular para a Rede Pública; que o Cedep possui um grande potencial de influência e de turbulência dentro das escolas públicas do Paranoá. Jesus (2007) ainda defende, como continuidade da pesquisa, que o Cedep se assuma como parte constituinte da educação pública no e do Paranoá-Itapoã, a partir de sua experiência e aprendizado históricos na Educação Popular. 
Salienta, ainda, sobre a importância de pensarmos estratégias para que Movimento Popular e Governo possam construir uma mudança dentro do sistema público de ensino do Paranoá-Itapoã (JESUS, 2007, p. 105).

Viana (2012) completa a incompletude das pesquisas de Lima (1999) e de Jesus (2007), ao investigar os estudantes da Universidade que são egressos da experiência no Projeto Paranoá-Itapoã. Uma tríade de dissertações que investiga o efeito repercussão do Projeto. Sua principal indagação de pesquisa é:

como a trajetória formativa dos (as) egressos (as) do Projeto Paranoá repercute em suas atuações profissionais? Numa perspectiva de Educação Popular e de contra-hegemonia, quais são os enfrentamentos, as superações e as possibilidades diante das suas atuações como pedagogos(as)?" (VIANA, 2012, p. 54).

Contra-hegemonia compreendida como uma proposta que rompe com a hegemonia educacional vigente: "uma luta de hegemonias políticas, de direções contrastantes, primeiro no campo da ética, depois no da política, atingindo, finalmente, uma elaboração superior da própria concepção do real" (GRAMSCI, 1999, p. 103).

O recorte de Viana (2012) perfaz o período de 1986 a 2010, 26 anos de projeto. Desse intervalo de tempo, lista todos os estudantes da UnB que passam pelo trabalho do Paranoá. Identifica 89 egressos, sendo 48 pedagogos e 41 de cursos como Letras, Psicologia, Ciência Política, Engenharia, entre outros (VIANA, 2012, p. 84). Dos 48 pedagogos identificados como egressos, 23 são professores da Secretaria de Educação do Distrito Federal -SEEDF; 12 não atuam na área de educação; e 13 atuam como pedagogos de organizações educativas, como Serviço Nacional de Aprendizagem Industrial - SENAI, Ministério da Educação - MEC, Instituto Nacional de Estudos e Pesquisas Educacionais Anísio Teixeira - INEP, Universidade Estadual de Campinas - Unicamp, Universidade Católica de Brasília - UCB, Centro de Cultura e Desenvolvimento do Paranoá Cedep, Ministério das Comunicações - MC e Ministério do Desenvolvimento Social - MDS, dentre outros. 
Ainda sobre pedagogos egressos, seleciona os que têm no mínimo dois anos de Projeto, os que participam do encontro do Mantendo a Caminhada e os "que trabalham direta e/ou indiretamente com o público da educação de jovens, adultos e idosos" (VIANA, 2012, p. 62). O termo "direta" é usado para qualificar os que estão em sala de aula com o público jovem, adulto e idoso; e, indiretamente qualifica os que trabalham tendo como foco esse público, mas não estão em sala de aula. Por exemplo, atuação em programas e projetos governamentais que têm como foco a Educação de Jovens, Adultos e Idosos Trabalhadores - EJA. Dos dois últimos recortes, encontra cinco egressos que trabalham com EJA, sendo três diretamente e dois indiretamente.

Esclarecemos que o encontro do Mantendo a Caminhada é uma reunião mensal realizada aos sábados, no horário das $15 \mathrm{~h}$ às 17h30, pelo Grupo de Ensino, Pesquisa, Extensão em Educação Popular e Estudos Filosóficos e Histórico-Culturais - Genpex/FE/UnB. Esses encontros ocorrem desde o ano 2000, quando da constituição do Genpex como grupo de pesquisa cadastrado no Diretório de Grupos do Conselho Nacional de Desenvolvimento Científico e Tecnológico - CNPq. É um encontro que vem se constituindo com dois objetivos mais prioritários: o fortalecimento da produção de conhecimento práxico do grupo e a continuidade da interlocução entre os egressos do Genpex/FE/UnB e a Universidade, numa oxigenação mútua.

Viana (2012), para aprofundar sua compreensão de seu objeto de estudo, realiza entrevistas com os cinco egressos que atendem aos critérios estabelecidos. Das entrevistas, destaco alguns aprendizados que são considerados como repercussão na vida dos pedagogos egressos do Projeto Paranoá-Itapoã. O primeiro é o sentido que essa ação conjunta traz para o próprio percurso da graduação em Pedagogia, quando garante a indissociabilidade teórico-prática. As falas dos sujeitos dessa pesquisa corroboram que essa é uma contribuição fundamental do Projeto Paranoá-Itapoá:

[...] A maioria das disciplinas da FE eram disciplinas comuns como qualquer outra, e que não tinham espaço de interação, de reflexão e de ação sobre a realidade. Então, o nosso espaço mais dinâmico de 
tentar exercitar aquilo que você aprendia nas disciplinas era o Projeto Paranoá. (VIANA, 2012, p. 69).

Viana (2012) toca em uma questão que alicerça o fazer ciência do Genpex/FE/UnB: a práxis. Para isso, é fundamental retomar a compreensão de ciência trazida por Gramsci, em que o cientista é um operário que busca a unidade teoria-prática como mediação dialética entre ser humano e natureza:

Entende-se por ciência a atividade teórica ou a atividade prático-experimental dos cientistas? Ou a síntese das duas atividades? Poder-se-ia dizer que reside nisso o processo unitário típico do real, ou seja, na atividade experimental do cientista, que é o primeiromodelo de mediação dialética entre o homem e a natureza, a célula histórica elementar pela qual o homem, pondo-se em relação com a natureza através da tecnologia, a conhece e a domina [...] A experiência científica é a primeira célula do novo método de produção, da nova forma de união ativa entre o homem e a natureza. O cientista experimentador é um operário, não um puro pensador; e seu pensar é continuamente verificado pela prática e vice-versa, até que se forme a unidade perfeita de teoria e prática. (GRAMSCI, 1999, p. 166, grifos nossos)

Relação teoria-prática, que é marca histórica da ação conjunta Universidade de Brasília e Movimento Popular do Paranoá-Itapoã. Semanalmente, às quintas-feiras, ocorre na Faculdade de Educação da Universidade de Brasília o encontro de avaliação e reencaminhamento da práxis do Genpex/FE/UnB. Neste encontro, os estudantes-pesquisadores da graduação e pós-graduação avaliam o trabalho da semana, refletem e reencaminham a práxis, em sua continuidade processual. Movimento constante de ação-reflexãoação em busca de superar as situações-problemas-desafios (REIS, 2000, 2011) da caminhada. Na pesquisa de Viana (2012), esse movimento práxico ocasionado pelo Projeto Paranoá-Itapoã é ressaltado pelos sujeitos como indispensável para o processo de constituição do pedagogo: 
No currículo de Pedagogia da FE-UnB, a maioria das disciplinas curriculares fica apenas na teoria e não proporciona aos estudantes o desafio da criação e da resolução de problemas com o enfrentamento da realidade. Nessa perspectiva, a ausência de diálogo entre os sentidos reais e existenciais e os conhecimentos teóricos não fornece condições para uma formação que desenvolva vínculos pessoais e profissionais significativos e que integre a totalidade do ser. (VIANA, 2012, p. 70, grifo nosso)

Formação que desenvolva vínculos pessoais e profissionais, que integre teoria e prática, essa parece ser uma contribuição fundamental para os pedagogos egressos do Projeto Paranoá-Itapoã. Ainda sobre essa temática de formação de vínculos, integração teoria-prática, os sujeitos da pesquisa ressaltam a importância da formação de redes. Citam o encontro do Mantendo a Caminhada como estratégia que proporciona a continuidade desse aprendizado depois da conclusão do curso:

Mesmo que esteja numa escola sozinha lá, claro que isso eu vejo assim, lá na escola tem que se buscar essa coletividade e no Mantendo a Caminhada a gente tem que irradiar isso na nossa ação e atuação profissional e isso é muito importante. (VIANA, 2012, p. 77).

Buscar a coletividade, uma ação-reflexão-ação, seja na escola em que se trabalha, seja no Mantendo a Caminhada, como reforço a essa luta de não ficar sozinho (a), isolado(a). O aprendizado do estar, fazer, exercitar enfrentamentos conjuntos, aparece nos quatro trabalhos, de Reis, Lima, Jesus e, agora, Viana. Uma marca singular dessa ação conjunta Genpex/FE/UnB e Cedep.

Outra repercussão dessa parceria, ressaltada pela pesquisa de Viana (2012), é sobre o método de trabalho: "o método de trabalhar com a situação-problema-desafio te ajuda e muito a não ficar lamentando o problema" (VIANA, 2012, p. 80). Não lamentar o problema, mas buscar superá-lo; não sozinho, mas junto de um coletivo. Isso que dá força, como eu destaco em minha entrevista a 
Viana. "[...] tenho essa força porque fui me constituindo, no Projeto Paranoá, a ver um problema e superar um problema e isso me ajuda muito tanto no MEC quanto na minha vida pessoal em vários aspectos. Isso é a marca do Projeto Paranoá" (VIANA, 2012, p. 80). Novamente, a busca da superação das situações-problemas-desafios como ato do tornar-se humano, cada vez mais humano. Não lamentar o problema, mas criar alternativas, soluções, ser criatura e criador.

\section{CONCLUSÃO}

As pesquisas de Reis (2000, 2011), Lima (1999), Jesus (2007) e Viana (2012) complementam-se e aprofundam-se, ao analisarem a repercussão da trajetória de educandos(as), educadores(as) e pedagogos(as) que são constituídos pela parceria Genpex/FE/UnB e Cedep. Trazem para nós vozes e sentidos que vêm sendo delineados ao longo da trajetória histórica dessa costura. Trabalhos que estão tecidos, costurados, que se fortalecem mutualmente.

Em Reis (2000, 2011), sublinho a voz e o sentido da constituição humana pelo entrelaçamento do ser de amor-poder-saber. O ser de amor, como aquele que acolhe e é acolhido, que escuta, que olha, que chama pelo nome, que considera o outro, que conforta, que abraça; o ser de poder, como aquele que tem e exerce poder, que decide, que escolhe e busca superar as situações-problemas-desafios individuais e coletivas, que participa dos espaços deliberativos em sala de aula e na comunidade; o ser de saber, que possui e constrói conhecimento, construção do conhecimento que se consubstancia em um texto coletivo (oral e escrito), a sala de aula como espaço de troca de saberes, em que cada um contribui com o que é, o que sabe. Onde todos são, podem e sabem.

Lima (1999) traz com intensidade a voz e o sentido da participação popular e do aprendizado de que problema é para ser superado. Não uma participação que tem como limite a legalidade instituída, mas uma participação popular que defende a transformação da sociedade, uma nova sociedade, uma nova legalidade que permita a realização plena individual e coletiva dos seres humanos. O aprendizado de que problema é para ser superado, 
é ponto que precisa ser enfatizado da fala do educando egresso da Educação Popular, que não desiste de prosseguir seus estudos. Enfrenta os desafios da Escola Pública como condição para avançar e se tornar humano, superando as exigências de existência e sobrevivência.

Em Jesus (2007), a voz e o sentido do coletivo são destacados pelos educadores egressos da Educação Popular do Paranoá-Itapoã, ao se inserirem na Rede Pública. Sentem na Rede Pública o isolamento. Isolamento que não quer dizer simplesmente falta de reunião conjunta, mas de um encontro coletivo que tem como natureza a acolhida humano-existencial. Nesse encontro, tem-se o tempo e a disposição para escutar o outro, os múltiplos pontos de vista. Lugar de encontro em que cada um pode ser o que é, sem hierarquias e centralidades.

Finalmente, com Vianna (2012), emerge a voz e o sentido da práxis, relação teoria-prática, que é ressaltada pelos pedagogos egressos da UnB como singularidade da ação conjunta Genpex/FE/UnB e Cedep. Reforçam como essa relação de açãoreflexão-ação permanente traz sentido para o tornar-se pedagogo e vai de encontro à perspectiva hegemônica de organização dos currículos de formação de professor que pressupõem uma formação teórica inicial para, posteriormente, uma inserção na realidade. $\mathrm{Na}$ parceria Genpex/FE/UnB/Cedep isso é diferente. O graduando e a graduanda, já no início de seu percurso formativo, inserem-se em um real-concreto ocorrente, a partir das situações-problemas-desafios vivenciadas, e planejam, avaliam e reencaminham cotidiana e coletivamente as ações-reflexões-ações, para seu enfrentamento. Movimento formativo em que teoria e prática são indissociáveis.

Em suma, podemos enumerar as seguintes singularidades da ação conjunta Genpex/FE/UNB/CEDEP: um processo constitutivo de sujeitos, educandos, educadores e estudantes da UnB, que ocorre a partir do entrelaçamento do ser de amor-poder-saber; o aprendizado dos educandos de que problema é para superar e não desistir; o aprendizado dos educadores de que é no coletivo que nos constituímos; e, por fim, o processo formativo dos estudantes de Pedagogia da UnB que acontece, fundamentalmente, na relação teoria-prática. 


\section{REFERÊNCIAS}

BAKHTIN, Mikhail. Estética da criação verbal. 5. ed. São Paulo: Editora Wmf Martins Fontes, 2010.

BRASIL. Lei n 9.394, de 20 de dezembro de 1996. Estabelece as Diretrizes e Bases da Educação Nacional. Diário Oficial da União: Brasilia, DF, 23 dez. 1996. Disponível em:

http://www.planalto.gov.br/ccivil_03/leis/19394.htm. Acesso em: 13 jan. 2021.

ENGELS, Friedrich. A Dialética da Natureza. Rio de Janeiro: Paz e Terra, 1979

GRAMSCl, Antônio. 1891-1937 Cadernos do cárcere. Rio de Janeiro: Civilização Brasileira, v. 1, 1999.

JESUS, Leila Maria de. A repercussão da atuação de educadores/as populares do Cedep/UnB na Escola Pública do Paranoá-DF. Dissertação (Mestrado em Educação) - Faculdade de Educação, Universidade de Brasília. Brasília: 2007.

LIMA, Airan Almeida de. Participação e Superação do Fracasso Escolar.

O caso do Projeto de Alfabetização de Jovens e Adultos da cidade do Paranoá-DF. Dissertação (Mestrado em Educação) Faculdade de Educação, Universidade de Brasília. Brasília: 1999.

MARX, Karl; ENGELS, Friderich. A Ideologia Alemã. São Paulo: Martins Fonte, 1998.

PINO, Angel. O social e o cultural na obra de Vigostki. In: Educação \& Sociedade. Revista Quadrimestral de Ciência da Educação.

Campinas, Centro de Estudos Educação e Sociedade (Cedes). n 71, 2. ed., p. 45-78, 2000.

REIS, Renato Hilário. A constituição do ser humano: amor-podersaber na educação/alfabetização de jovens e adultos.Campinas, SP: Autores Associados, 2011.

REIS, Renato Hilário. A constituição do sujeito político, epistemológico e amoroso na alfabetização de jovens e 
adultos.Tese (Doutorado em Educação) - Faculdade de Educação, Universidade de Campinas. Campinas: 2000.

REIS, Renato Hilário. Alfabetização Enquanto Saber, Poder e Cidadania: O projeto de alfabetização e de formação de alfabetizadores de jovens e adultos de camadas populares da vila paranoá-DF.Faculdade de Educação/UnB, 1995, mimeo.

SOBRAL, Julieta Borges Lemes. Dialogando vozes e sentidos da Educação Popular e da Educação de Jovens e Adultos na Rede Pública de ensino do Distrito Federal. Tese (Doutorado em Educação) - Faculdade de Educação, Universidade de Brasília. Brasília-DF, 2018.

VIANA, Sttela Pimenta. As significações e repercussões do percurso formativo de pedagogos(as) egressos(as) do Projeto Paranoá em suas trajetórias profissionais na Educação de Jovens e Adultos. Dissertação (Mestrado em Educação) - Faculdade de Educação, Universidade de Brasília. Brasília: 2012.

VIEIRA, Maria Clarisse; RIOS, Guilherme Veiga; REIS, Renato Hilário dos (orgs.). As significações do texto coletivo no processo alfabetizador de jovens e adultos do Cedep/Paranoá e Itapoã UnB. Editora da Universidade de Brasília, 2020.

VIGOTSKI, L. S. Lev S. Vigostki: Manuscrito de 1929. Educação \& Sociedade. Revista Quadrimestral de Ciência da Educação Campinas, Centro de Estudos Educação e Sociedade (Cedes). n 71, 2. ed., VXXII f. IX. 2000.

Submetido em: Junho/ 2021.

Aceito em: Agosto/ 2021. 